\title{
Ethical Naturalism and Forms of Relativism
}

\author{
Tony Lawson
}

Published online: 15 October 2013

(C) Springer Science+Business Media New York 2013

Like Philip Gorski I adhere to an ethical naturalist position that in turn underpins a moral realist orientation (e.g., Lawson $2000,2003 \mathrm{~b}, 2007)$. Moreover the versions of ethical naturalism that Gorski and I accept seem similar, though Gorski would have to elaborate more for me to determine if they are identical. In any case, although I might express my own position somewhat differently I find much in the paper with which to agree. Certainly I think ethical naturalism grounds the possibility of social science contributing to underlabouring for a better world. And I much agree with the thrust of Gorski's main argument. I will make some comments upon the fact/value or description/prescription distinction as it relates to ethical naturalism. But, on the assumption that critical engagement is more interesting than agreement, I mostly focus, instead, on what is something of a side issue, namely Gorski's rejection of both cognitive and moral relativism. I wonder if either rejection is really necessary for, or justified by, Gorski's ethical naturalism. Or to put things differently, I wonder if it is not something else that Gorski is really opposing, or at least something contestable that should be differently named. In considering both cognitive and moral relativism, I follow Gorski by turning to the contributions of Steven Lukes to provide the arguments. In both cases I wonder if Luke's claims can really be sustained.

\section{Cognitive Relativism}

Although Gorski informs us early on that "Lukes is ultimately - and rightly - unpersuaded by cognitive relativism" the intended meaning of the latter is not altogether clear. Lukes

T. Lawson $(\bowtie)$

Faculty of Economics, University of Cambridge, Austin Robinson

Building Sidgwick Avenue, Cambridge CB3 9DD, UK

e-mail: tony.lawson@econ.cam.ac.uk starts the relevant section of his book by posing the following question: "Is what we can know determined by a world that is independent of us, or is it, in some sense, "up to us"? The former option clearly presupposes a (philosophical) realist position (which with his acknowledged neo-Aristotleanism and ethical naturalism I assume Gorski embraces explicitly) whilst the latter is seemingly intended to signal Luke's understanding of the nature of cognitive relativism.

It might seem then that Lukes is opposing his cognitive relativism with philosophical realism Strictly speaking, however, philosophical realism is merely the doctrine that there exists a reality (at least in part) independently of us, a doctrine that implies nothing per se about how our 'knowledge' is formed. At the same time most if not all realists accept that there is a sense in which all of what we regard as knowledge, and indeed all of social reality, is a social construction: it is created by interacting human beings. The thesis that a realist does not accept is that truth itself is a social construction. Truth, on the realist conception, is a relation between any knowledge claims and the real world, and so is an objective matter; the truth content of any proposition or belief depends on the way the world is.

But the latter is quite consistent with relativism in knowledge construction. We, all of us, form views from somewhere. We are all differently situated, with unique life paths, and sets of experiences, on the basis of which our cognitive frameworks and perspectives have been shaped. This sort of relativism is accepted by all except the most naive of realists (and elsewhere I argue that it is actually essential to epistemological endeavour. See e.g. Lawson 1999, 2003a). This however seems, at least at times, to be Luke's cognitive relativism, which, according to Gorski, Luke's is correct to reject.

The form of relativism that most realists do instead reject is the notion that where knowledge claims conflict it is never possible to interact and experiment on the world in ways that allows rational discrimination. The ability to discriminate entails 
a judgemental rationality; the denial of this ability is not a cognitive but a judgemental relativism. Certainly the actual acceptance of theories will in practice always be affected by much else besides ontological/evidential considerations, including power relations, modes of rhetoric and so forth. But, for the realist, only the judgemental-relativist claim that comparative evaluation is in principle impossible, is in any way problematic.

A difficulty with Luke's analysis is that he is less than clear on many of these issues. He writes, for example, that for the cognitive relativist: "There is no 'true world' that is really objective but unknown to us humans. There are indefinitely many possible perspectives from which knowledge is to be had, and there is no prospect of their being brought to converge within a true, comprehensive theory of the world. This thought becomes fully relativist when the idea of perspectives is tied to particular groups within humanity. Now the idea is that potentially all our ideas and theories are to be seen as local cultural formations, rooted in and confined to particular times and places, and that there is no independent "truth of the matter" to decide among them. This may in turn suggest that we as human beings have no shared standards on the basis of which we can understand one other. Now there are multiple 'we's,' each with 'our' own standards of truth, reasoning, and morality." (Lukes, 2008, pp. 2-3) The first sentence is clearly ambiguous. By there being no objective "true world" does Lukes mean there is no independent reality or is he allowing it but claiming that objective true knowledge about it is impossible? In any case, and fundamentally, it is not necessary to make either claim in order to accept the second sentence, that there 'are indefinitely many possible perspectives from which knowledge is to be had'. And when Lukes adds that 'there is no prospect of [the independent perspectives] being brought to converge within a true, comprehensive theory of the world' one wonders why we should be bothered about perspectives converging and what the role of the term 'comprehensive' is here. Nor is realism threatened by the idea that perspectives may in some sense be 'tied to particular groups within humanity'.

The notion of varying standards of truth presumably means that there are varying criteria whereby differently situated individuals discriminate between competing theories. If this entails the idea that different accounts cannot be rationally compared at all, it is in the end a position that most realists will likely contest. But, so interpreted, it comprises a judgemental not a cognitive relativism. It rests not on the relativity of all knowledge claims but on the rejection of ontological realism, on a denial of the possibility that intervention in the world facilitates a judgemental rationality in theory discrimination.

Though Gorski accepts Lukes terminology I take it that it is such a judgemental (not a cognitive) relativism that Gorski too rejects: "Cognitive relativism encompasses facts as well as values. In its strongest forms, exemplified by "science studies", cognitive relativism implies that theory choice is not simply under determined by evidence but that it is altogether undetermined by evidence. On this reading, exogenous or external factors - "power", "networks", "culture" and so on - are the crucial factors. From this perspective, we have no reason to prefer the physics of Einstein to the magic of the Azande. They are both equally valid. Lukes is ultimately - and rightly - unpersuaded by cognitive relativism of this sort". I may be accused of playing with words here. But I think it is clear that two forms of relativism are being run together by Lukes and essential to distinguish which of the two, if either, must necessarily be rejected.

\section{Ethical Naturalism}

I worry, too. that unnecessary ambiguity of a similar sort may be involved in Gorski's rejection of moral relativism. To get to the issues that matter we need to be clear first on the nature of ethical naturalism. Gorski says relatively little about the latter, so let me elaborate my own understanding of the position. Ultimately ethical naturalism, certainly as I accept it, is a somewhat reductionist stance in that it holds that there are no emergent (or certainly no transcendent or free floating) moral properties that are irreducible to the (rest) of the real/natural world. Rather ethical or moral terms - such as good, bad, right and wrong, etc., - pick out features of the world that can be, and typically are, simultaneously referred to in more clearly naturalistic terms (such as human well-being, interest, action facilitative of human well-being, and so forth). In other words, moral terms share the same referents as non-moral terms. Alternatively put, ethical naturalism insists that if there exist moral properties and/or what some philosophers like to call facts, these are identical with natural properties (and facts).

An argument thought to undermine ethical naturalism, one that Gorski treats at length, turns on the assessment, usually associated with David Hume, that an 'ought' cannot be derived from an 'is', that a prescriptive claim cannot be derived from merely factual or descriptive claim. As Hume puts it: "Since morals, therefore, have an influence on the actions and affections, it follows, that they cannot be deriv'd from reason; and that because reason alone, as we have already prov'd, can never have any such influence. Morals excite passions, and produce or prevent actions. Reason of itself is utterly impotent in this particular. The rules of morality, therefore, are not conclusions of our reason." (Hume, 1739, p. 457)

I take it that this is thought to undermine ethical naturalism in the following way. If we leave moral/ethical issues aside then we have accounts of the way the natural or material (including the social) world is structured and works. The latter though do not allow the derivation of any 'oughts' or prescriptive assessments. These must then come from somewhere else, namely our values which as such cannot have naturalistic referents. So there must be a separate and irreducible moral domain and ethical naturalism is undermined. Alternatively put, there are factual judgements and 
evaluative ones, and these are held to be fundamentally different, with only the former having naturalistic referents. As a result factual judgements by themselves cannot entail evaluative ones. This, as I say, I am assuming is thought to undermine any project of ethical naturalism.

But consider the following:

A house with occupants is on fire, and the only way not to be burnt is to leave. Therefore the occupants ought to leave.

This seems to generate an 'ought' from mere 'is' statements. Why then might this reasoning be regarded as faulty? Why does the factual belief that the 'house is on fire, and the only way not to be burnt is to leave' not motivate the action of leaving the house. The response, as I understand it, would be that this explanation of conduct is incomplete. We must include additional appropriate attitudes or orientations, namely that the occupants do not want to burn. And doing so renders ought judgements fundamentally different to factual ones. Ought judgements are motivating in a way that factual judgements are not, and this is so because they, or moral beliefs, connect with 'sentiments' or feelings.

So why not include factual statements about feelings or preferences or interests etc. in the reasoning. For example what is wrong with the following?

The occupants of a house do not want to get burnt. The house is on fire, and the only way not to be burnt is to leave. Therefore the occupants ought to leave.

Here we find an ought-statement following from purely isstatements. As far as I can see there is nothing wrong here with the assessment that prescriptive statements can follow from merely descriptive ones. Hume is wrong then to say we cannot get an ought from an is. What does seem to be correct is that we cannot draw conclusions about conduct without assessments of what is in the interests of a relevant group of subjects, their needs and desires or whatever. The point, then, is that a naturalistic theory is not undermined by considerations of how prescriptive assessments are formed, but rather it is recognised that factual assessments must include judgements of interests (not wanting to be burnt), which in turn explain why other factual judgements (the house is on fire) constitute reasons for action (leaving the house).

\section{Taking a Stand}

This, however, is precisely what ethical naturalist positions do; they advance substantive theories about human interests. Of course, up until this point I have been writing only about the position of ethical naturalism; I have adopted an outsider perspective. But to say more, and indeed to hold (as opposed to talk about) an ethical naturalist stance it is necessary to take a stand. This requires committing oneself to a specific social theory, and specifically to a definite account of that which has so far been described as the human interest. Here I draw on my own research reported elsewhere, and can but summarise (fallible) results that bear clear relevance (see for example, Lawson 2003a, 2003b, 2012). According to it:

1) Human beings have natures such that each does indeed have 'interests'; more usefully human beings are the sorts of beings that can flourish.

2) Morality exists throughout the human world. People everywhere act in accordance with assessments of actions that are right or wrong or good and bad.

3) Human interests, the bases of our conditions for flourishing, that allow each to flourish, do not reduce to our preferences. Rather each human being is a bundle of needs and capacities and so forth, where flourishing depends on the fulfilment of these needs and capacities. It follows that we can all make mistakes about what actually is in our interests (false consciousness exists, actually existing moralities can be criticised and moral subjectivism false), and no reason to suppose that there is a unique way of meeting these interests.

4) Some of human needs and capacities are shared/universal (e.g., needs and/or powers to develop capacities of language use; or to generally to partake in forms of social interaction) and others not. All are developed in specific historical and socio-cultural contexts. And all are in some ways subject to continuous transformation.

5) Human beings are inherently relational. By this I do not mean that we are embedded in society. Rather we are socialrelationally constituted. From the moment we are conceived we are being socially moulded. And from Birth onwards, if not earlier, we are positioned according to gender, class, nation, culture and so on. According to our positions we have rights and (eventually) obligations, that relate us to others, whether similarly positioned or positioned contrastively (with our rights matched by 'their' obligations and so on). We are thus necessarily relational beings.

6) It follows from 5) that our flourishing is bound up with the flourishing of others. Indeed it is in the interests of each of us that others around us, and ultimately everyone, flourishes, no matter what our similarities and differences, so long as the flourishing of any one is not necessarily undermining of the flourishing of others.

7) By similar reasoning to 5) and 6) we are born into nonhuman nature too, and constituted through our relations to it. Thus it is in our interests that all of nature flourishes, at least in so far as it is not (intrinsically) harmful to us.

If terms like good or goodness have the same referent as human interests as construed here, we can say that the ultimate ethical good is human flourishing, in conditions where the flourishing of each and any of us is a condition of the flourishing 
of all others. So the goal of moral activity is a form of society that provides such conditions. The latter can be called the good society or eudemonia, as Gorski notes. It seems to be the sort of formation that Marx and Engels contemplated when, in the Communist manifesto, they write of an "association, in which the free development of each is the condition for the free development of all'.

Given that there are obstacles blocking the achievement of any such good society, including those that prevent each of us from recognising that our own real interests include the flourishing of all others, then action that can be considered derivatively or morally good or right, is action oriented to removing such obstacles. Of course, of the imaginable forms of action that could be utilised to remove such obstacles, only those that are consistent in themselves with the goals of human flourishing, qualify as morally good (the good society cannot be brought about by harming or eliminating those that are slow to recognise its value).

Why is this ethical naturalism a form of moral realism? I have suggested that (axiological) goodness relates to human flourishing, and that this requires conditions in which we can all flourish in our differences. Hence an objective or action is derivatively morally good or right if it contributes to fulfilling this end, to moving us towards eudemonia. Clearly whether or not an action or objective does fulfil this criterion is something about which we may, in forming a judgement, be mistaken. Morally good objectives for us to adopt exist independently of our knowledge of them. Specific judgements that certain objectives or actions are (morally) good in the relevant sense (in removing obstacles to eudemonia) will be correct or incorrect, independently of what we conclude. So the position is clearly a moral realist one in a fairly strong sense. Indeed to the extent that all actions and objectives are affecting of others, all are moral. The social and the moral domain essentially have the same referent.

How do we seek to identify morally good objectives and actions? Through empirically informed processes of reasoning, oriented to identifying, and forming strategies for transforming, structures and practices that obstruct (the path towards achieving) generalised human flourishing. Such processes are obviously fallible. But then so are the reasoning processes followed in any other form of science. On this view, of course, the plurality of actually existing moralities can be (fallibly) explained, evaluated and criticised and transformative programmes formulated (at best in democratic forums).

As far as I can see Gorski's position is by intent fairly similar. He writes for example that: "Moral realism comes in various forms. The one that will be defended here is a form of ethical naturalism. It presumes that human beings "flourish" under certain conditions and falter under others, much like other living beings. It further presumes that human beings have evolved to be social animals, whose "well-being" is partly determined by the kind of social order they live in - and not merely by the amount of wealth it generates." Gorski thereby accepts that there is an objectivity to moral theorising as science, that there is an independent fact of the matter regarding good objectives and actions, and that these exist to be uncovered. I take it this is what he means when he writes that "The object of these investigations is a middle kingdom of moral facts, situated somewhere between the realms of fact and value, an independent territory, containing discoverable truths about the good life and the good society.

The issue I want to address, though, is Gorski's rejection of moral relativism. Gorski signals his intention in this regard by announcing in his introduction that "Part III critiques arguments in favor of moral relativism advanced by a number of leading social theorists, focusing especially on Steven Lukes." In that section Gorski writes: "Lukes [...] seeks to defend a form of moral relativism. This kind of relativism, as Lukes defines it, applies only to "norms" or "values." It is seeded through a growing awareness of human cultural diversity. It takes root via reflection on the socio-historical contingency of one's own moral commitments. And it grows out of a sense that cultural and moral diversity are connected and growing." However Gorski does not actually tell us what moral relativism is, other than as interpreted by Lukes it applies only to norms and values. I have argued above that, for the philosophical realist, an epistemological relativism is not a problem. All knowledge is situated and relative. Problem arises only where it is supposed that competing claims about the same object cannot be evaluated. This is judgemental relativism.

The feature of ethical naturalism that is significant here is that it amounts to the claim that ethics is every bit as cognitive as science. Moral realism takes the form of the doctrine that there is a realm of good or right objectives and possibly actions that need to be uncovered, and the moral theorist is fallibly concerned with attempting to do so. In this the moral theorist is always situated, with a specific cognitive framework. Epistemological relativism operates here too.

But so, too, a form of community relativism can be seen to be in play at the ontological level. This takes the form of a diversity of systems of social organisation, resting on social norms, all of which have a moral dimension. Certainly, the fact of a diversity of cultural norms is not per se a problem for the ethical naturalist. To the contrary, they are essential. All social norms are community properties, and all exist to coordinate interactions within the community. Or at least they do so to the extent that all members conform (like driving on a particular side of the road). So ceteris paribus the following of community norms contributes to the generalised good of community members; all have a moral dimension. This is so even if, as with driving on a given side of the road, the norms vary across communities, and in ways that are incompatible. The world is open, and there is no unique set of norms to facilitate human co-ordination. The diversity of norms is per se no threat to the ethical naturalist. 
Yet much of the time Luke's moral relativism seems not to go much further than recognising a diversity of norms across communities. He writes for example: "Moral relativism is the idea that the authority of moral norms is relative to time and place. Norms are rules that indicate which actions are required, prohibited, permitted, discouraged, and encouraged. Norms, we typically say, are external to individuals and "internalized" by individuals, and they guide individuals' behavior: they issue instructions to act or not to act" $(2008$, p. 16).

Underpinning this view is recognition that there exists a diversity of actual moralities, and in particular that moral norms vary from society to society, culture to culture, or group to group. In other words, the moral relativist, according to Lukes, emphasises that there are divergent views about what sorts of actions can be interpreted as right or good etc.

Lukes does add that moral relativist insists that differences in moral norms across societies can be irreconcilable. From this the moral relativist concludes that any attempt to universalise moral norms must be futile. As Lukes puts it: "From their observation of the fact of moral diversity and their view that this diversity is irreconcilable, moral relativists take the crucial step that defines full-fledged moral relativism. They hold that if the internal, participant's normative view of morality is taken to be universally applicable, reaching across space and time, then it is untenable. There is, they claim, no unique viewpoint from which moral norms are rationally compelling and universally binding" (2008, p. 21).

But even here I see nothing that an ethical naturalist need in principle reject. For according to ethical naturalism the (axiological) goal of facilitating generalised flourishing, corresponding to the ethical good, is metaphysically basic, and this grounds a realm of derivative (deontic) goals that can be classed as moral goods and bads, including societal rights and wrongs, obligations and so on; and these can be especially variable in nature.

In other words, the grounds for the diversity at the level of norms is not so much (or just) cognitive as ontological/ cultural. All moral norms are community dependent, they are the properties of emergent communities (Lawson, 2012), whether or not different communities happen to support the same norms. The feature that is universal is the criterion whereby the moral theorist decides whether norms ought to be followed, namely generalised human flourishing.

Moreover in terms of stipulating that forms of conduct must follow, the moral realist not only can readily accept the fact of variety, but accepts that rarely if ever will any form of conduct be universally applicable. Consider a principle such as "X must be avoided", where $\mathrm{X}$ may be lying, withholding something wanted, or whatever. Are there interpretations of X that constitute courses of action that are necessarily rationally compelling and universally binding from a moral realist standpoint? I suspect that whatever the $\mathrm{X}$ we can imagine scenarios were doing $\mathrm{X}$ is considered reasonable or acceptable given the context. But the reasonableness of the action here means promoting of human flourishing given the context. What I think we can do is drop the concern with societal norms, and argue from a reflection of a society based on generalise human flourishing that an $\mathrm{X}$ such as lying is always bad. It is bad transfactually, i.e., whatever the situation; but it is only wrong ceteris paribus. Just as gravity always 'pulls' the autumn leaf to the ground with a constant rate of acceleration, i.e., transfactually, any specific leaf will actually follow such a path only ceteris paribus; in actuality aerodynamic and thermodynamic forces may cause the autumn leaf to fly over roof tops and chimneys. Similarly moral principles may entail that lying is always bad, but in specific contexts countervailing moral claims may result in the conclusion that, in the given situation, lying is not a wrong course of action. So I am unconvinced that moral relativism of the sort in question, i.e., as conceived by Lukes, and seemingly opposed, at least in name by Gorski, is something that Gorski, given his ethical naturalism, actually needs to reject.

Typically, the moral realist does reject the idea that competing (not just different) assessments of moral or good action in a given context cannot be compared. This is certainly a form of judgemental relativism. Whether that is also what we want the term moral relativism to mean is something on which we need to be clear. From the cognitivist perspective of ethical naturalism, I suspect it is clearest instead to talk of, and distinguish between, cognitive and judgemental relativisms in ethical reasoning, where ontological considerations give reason to accept the former but to reject the latter.

I have used the invitation to comment on Philip Gorski's paper as an opportunity to raise some connected issues that have concerned me. A fundamental purpose of philosophical, not least ontological, discussion, as I understand it, is ground clearing, to seek clarification especially, laying the basis for more substantive ventures. And moral theorising, it seems to me, is a sphere of activity where clarity in the use of categories is sometimes especially lacking. Whilst meaning is often evident from, and sometimes even determined only through, use, it is also the case that use of terms is often so varied and contradictory, that active intervention, or anyway questioning, is required for a perspective to be understood. Philip Gorski's topic and claims are sufficiently important that I think it essential that scope for misunderstanding be reduced. If I have misunderstood Gorski at all the above will at least help reveal where clarification is required. None of this of course undermines Gorski's central claim that social science can help provide insights to facilitate a better world. Indeed, a social science grounded in an acceptance of ethical naturalism seems a likely essential ingredient in any attempts to understand the conditions of, and to remove obstacles to achieving, a situation of generalised human flourishing. 


\section{Further Reading}

Hume, D. 1739. Treatise on Human Nature. Penguin Classics, 1969, London: Penguin Books Ltd.

Lawson, T. 1999. Feminism, Realism and Universalism. Feminist Economics, 5(2), 25-59.

Lawson, T. 2000. Evaluating Trust, Competition and Co-operation. In Y. Shionoya \& K. Yagi (Eds.), Competition, Trust and Co-operationA Comparative Study. New York: Springer Verlag.

Lawson, T. 2003a. Reorienting Modern Economics. London: Routledge.

Lawson, T. 2003b. 'Ontology and Feminist Theorising', Feminist Economics, (9):1, March, pp. 119-150.Reprinted in John B. Davis (ed.) Recent Developments in Economic Methodology, 2006, Cheltenham: Edward Elgar

Lawson, T. 2003c. 'Theorising Ontology', Feminist Economics, (9):1, March, pp. 161-169.
Lawson, T. 2007. Gender and Social Change. In J. Brown (Ed.), The Future of Gender (pp. 136-62). Cambridge: Cambridge University Press.

Lawson, T. 2012. 'Ontology and the Study of Social Reality: Emergence, Organisation, Community, Power, Social Relations, Corporations, Artefacts and Money. Cambridge Journal of Economics, 36(2) pp $345-385$.

Lukes, S. 2008. Moral relativism. New York: Picador.

Tony Lawson is Reader in Economics at the University of Cambridge, Professor of Economics at the National University of Ireland at Galway and currently Professorial Research Fellow of the Independent Social Research Foundation. He is convenor of both the Cambridge Social Ontology Group and the Cambridge Realist Workshop, and is a former Director of the Centre for Gender Studies in Cambridge. His books include Reorienting Economics, (2003) and Economics and Reality (1997), both published with Routledge. 